\title{
RETAINING HAND BIOMECHANICS IN CASE OF A HAND TUMOR
}

\author{
Miklós Szokoly ${ }^{1}$, Petra Aradi ${ }^{2}$ \\ ${ }^{1}$ Péterfy S. Hospital and Trauma Center \\ ${ }^{2}$ Budapest University of Technology and Economics \\ szokoly@gmail.com
}

\begin{abstract}
The case of a patient with lung cancer is presented whose first metastasis was detected in the $5^{\text {th }}$ metacarpal head. Hand metastasis in lung cancer is a rarity in literature. After the detection of the hand tumor treatment was sidetracked by representatives of other medical specialities. The growing tumor destroyed the $3^{\text {rd }}, 4^{\text {th }}$ and $5^{\text {th }}$ metacarpals, thus based on DSA, MRI, CT, PET-CT and $\mathrm{X}$-ray results and thorough planning of the surgical procedures only opposition and grip of thumb and index finger was possible to form. During surgery unexpected difficulties occured partly because of the condtion of tissues, partly because the tumor was infected. It was not possible to plan exactly before the procedure due to the nature of the tumor, and according to the hystological results, the metastasis was cleared only by $6 \mathrm{~mm}$. It was possible to rescue the $2^{\text {nd }}$ metacarpal with the atypical insertion of an AO-plate, so that the final statics of the hand was secured. The postoperative period proved to be reassuring, however due to the quick progression of the underlying disease the patient was lost.
\end{abstract}

Keywords: metastatic hand tumor; function preservation

\section{Introduction}

The hand as a biomechanical unit is extremely sensitive to any small changes that affect the fine motion of thumb and long fingers, especially when a radical amputation becomes unavoidable due to either traumatological reasons or a tumor.

In this case review the treatment of a 51 years old patient with a rare hand tumor is followed from detection, till the function preserving radical intervention, during which we wished to keep the most of the hand's biomechanical unit.

\section{Case presentation}

The 51 years old woman was treated with COPD in the local dispensary for lung diseases since 2003.
End of January 2009 she detected a painful swelling on her right hand, in the $5^{\text {th }}$ metacarpal head. The routine X-ray showed a cystous osteolytic degeneration on the $5^{\text {th }}$ metacarpal. She had an accident at work on 2009-02-03, when the same $5^{\text {th }}$ metacarpal was injured. Based on the X-ray (Figure 1) a transverse fracture without dislocation just under the head of the $5^{\text {th }}$ metacarpal was described, and a cystous disorganization the size of a small bean was mentioned.

In the beginning of February 2009 a needle biopsy, a repeated chest X-ray and an MRI examination (Figure 2) were ordered.

The hypothenar needle biopsy of 2009-03-11 showed small and larger groups of atypical, polymorph tumor cells with wide cytoplasma near the blood elements. Based on the shown image a carinoma metastatis was suspected, and further cytochemical examinations were suggested. 


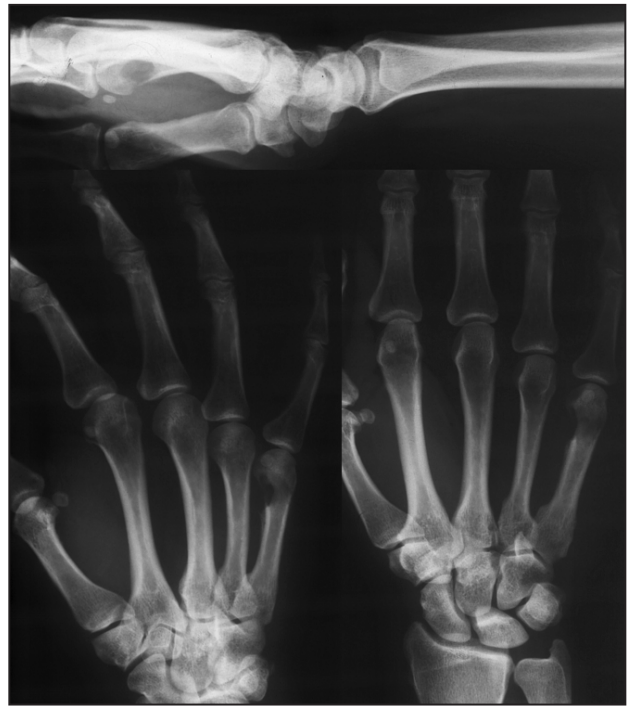

Figure 1. X-ray of right hand after the injury of 2009-02-03

Because of the patient's primary disease and a chest X-ray made in the local dispensary for lung diseases she was transferred to a pulmonology ward, where an exploration started to localize the primary tumor, during which a PET-CT examination was made (Figure 3).
The PET-CT showed a $4 \times 3 \mathrm{~cm}$ tumor in the left lower lung lobe with mediastinal and left axillary lymphnode metastases and two suspected $2 \times 1 \mathrm{~cm}$ lymphnode metastases in the right armpit.

Oncologists recommended palliative irradiation for the right hand, and the hand metastasis responded well both radiologically and macroscopically. After this treatment the patient was transferred back to the pulmonology ward and lost contact with her hand surgeon. A bronchoscopic test proved the tumor to be malignant. From May 2009 the pulmonary adenocarcinoma was treated with chemotherapy, Gemzar+CDDP. During this period the hand tumor was gradually growing, and the painful, malodorous, loose lump became increasingly intolerable for the patient.

Due to the increasing hand pain the patient was directed to an ambulatory pain center in September 2009. She first came to our hospital in October 18, and based on the hand status (Figure 4) and X-ray (Figure 5) a repeated checkup was started.

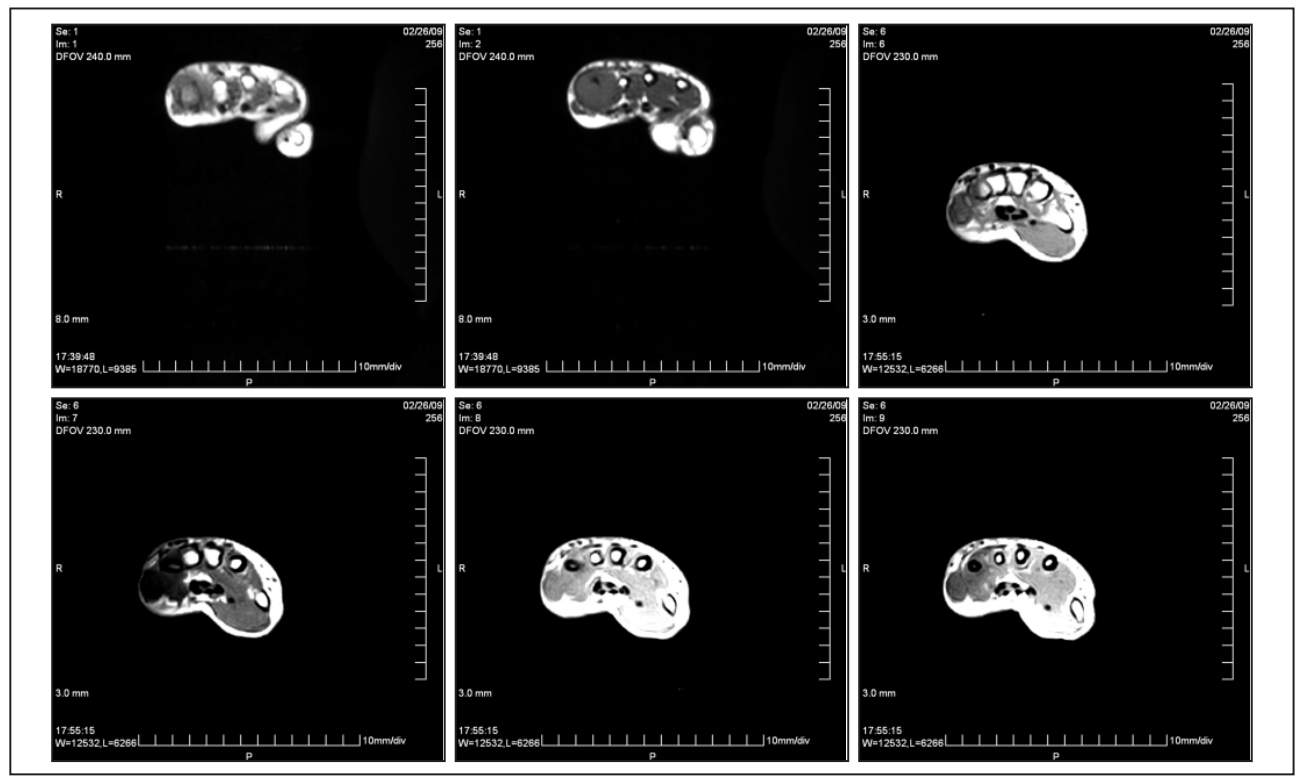

Figure 2. Right hand MRI images of 2009-02-26 


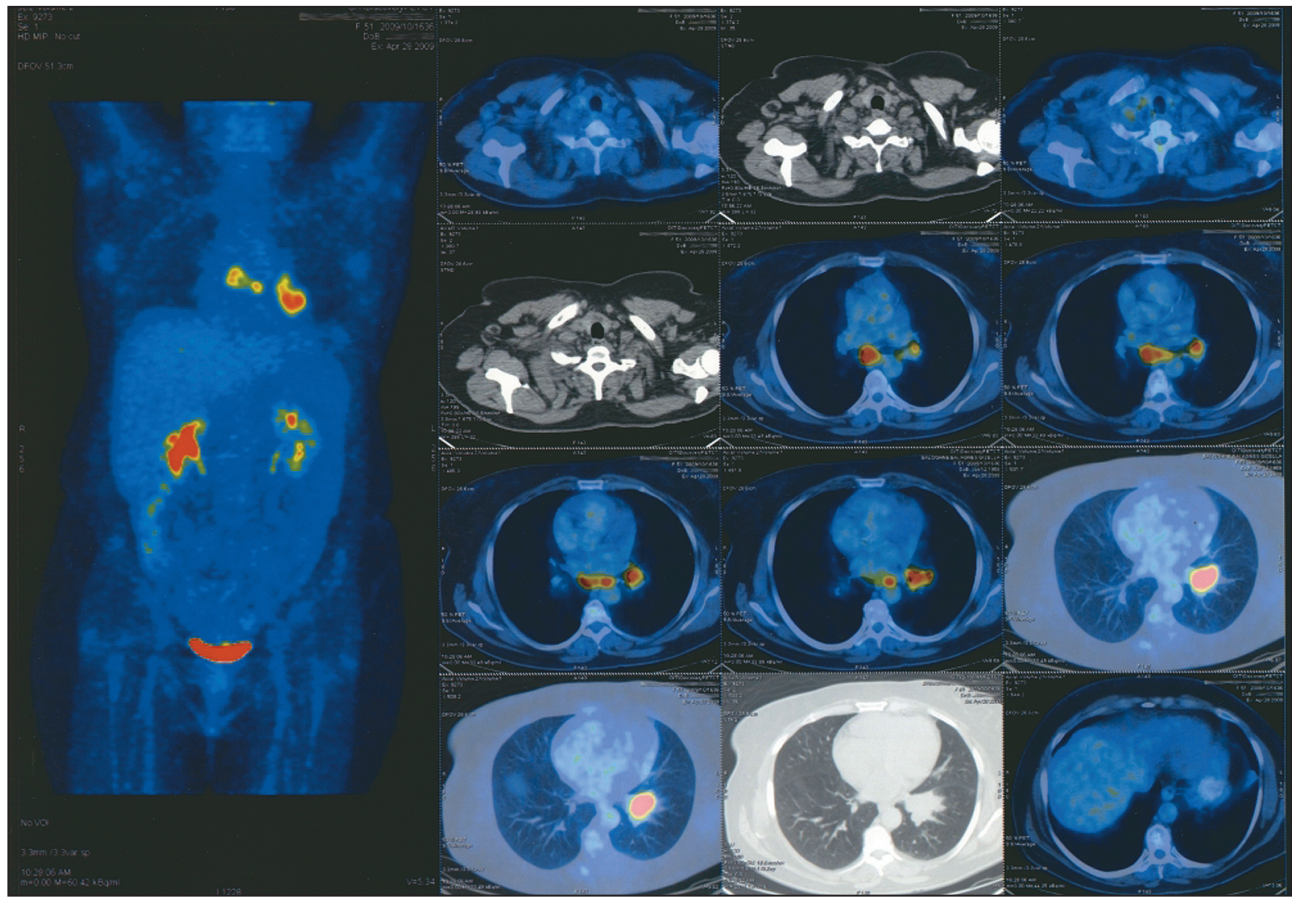

Figure 3. PET-CT images of 2009-04-28
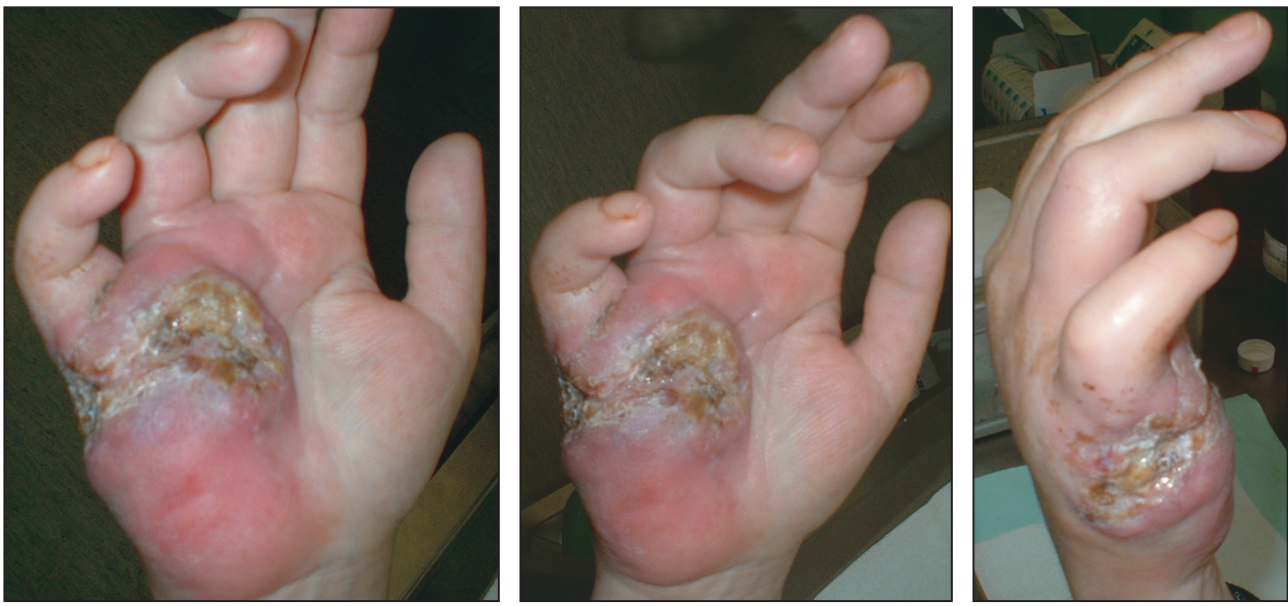

Figure 4. Hand status of 2009-10-18

Compared with the X-rays of February 2009 (Figure 1) the new X-rays (Figure 5) show the tumor's spreading and the osteolysis.
During the new checkup series beacuse of the urgency a CT was made 2009-10-27 (Figure 6), while the cytostatic treatment of the lung tumor continued in the pulmonological institution. 

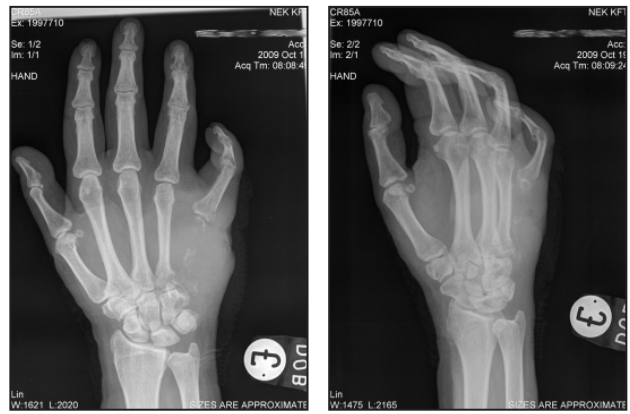

After the rapid checkup the patient was transferred back to the pulmonology ward where the cytostatic treatment went on. In the beginning of November the patient arrived in a severe septic condition to our hospital, beacuse the hand tumor became infected, disintegrated, malodorous (Figure 7) and made the life of not just the patient, but that of her family unbearable.

Figure 5. X-ray of 2009-10-19
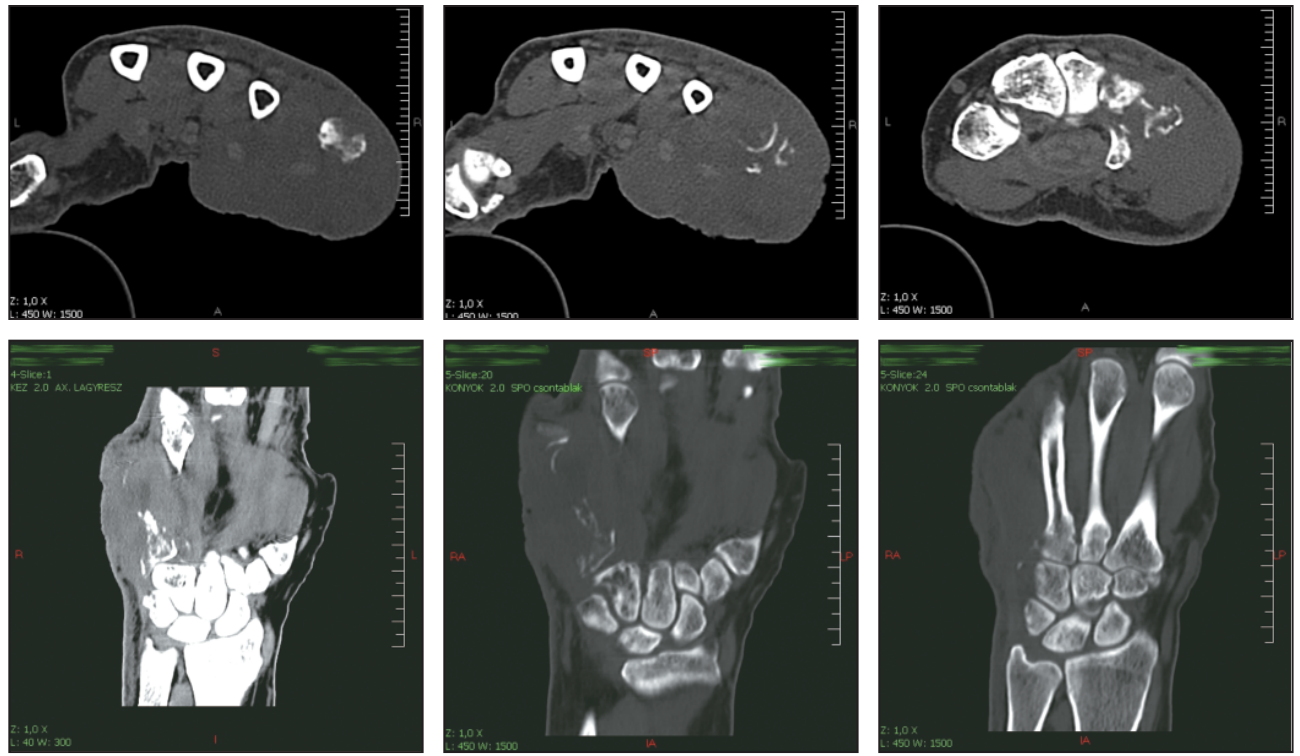

Figure 6. CT images of 2009-10-27
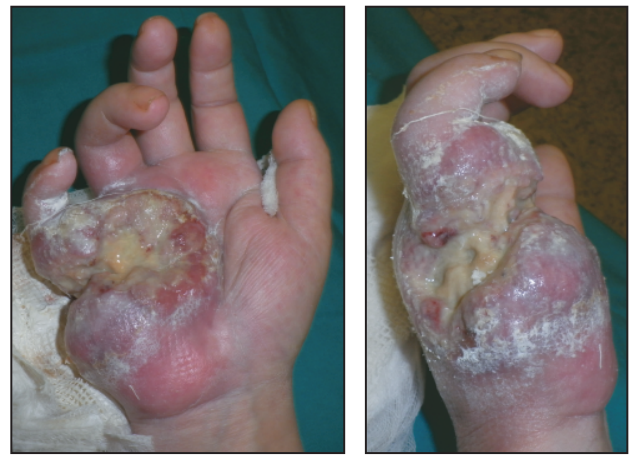

Figure 7. Hand status of 2009-11-03
When planning surgery it was imperative to assess the extent of the tumor and its blood supply, that is why further X-ray (Figure 8) and DSA (Figure 9) images were made.

According to the DSA results the brachial artery is moderately gracile, spastic, but with intact contours and the branches are retained. The antebrachial arteries fill normally. There are two incomplete arches on the palmar side. In the ulnar third of the palm there is an independent feeding artery coming from the distal 

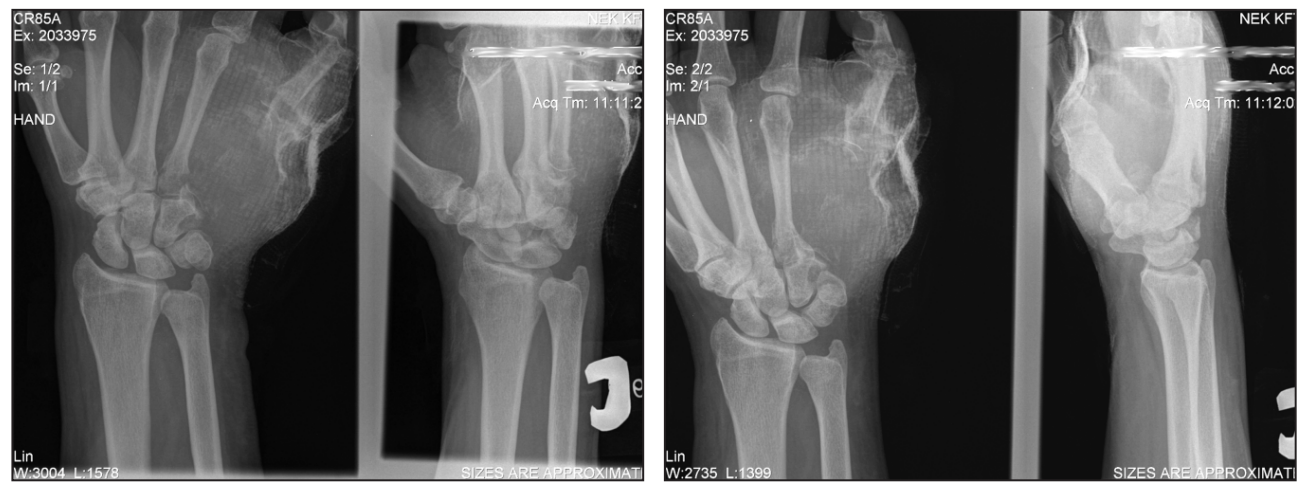

Figure 8. X-ray of 2009-11-13
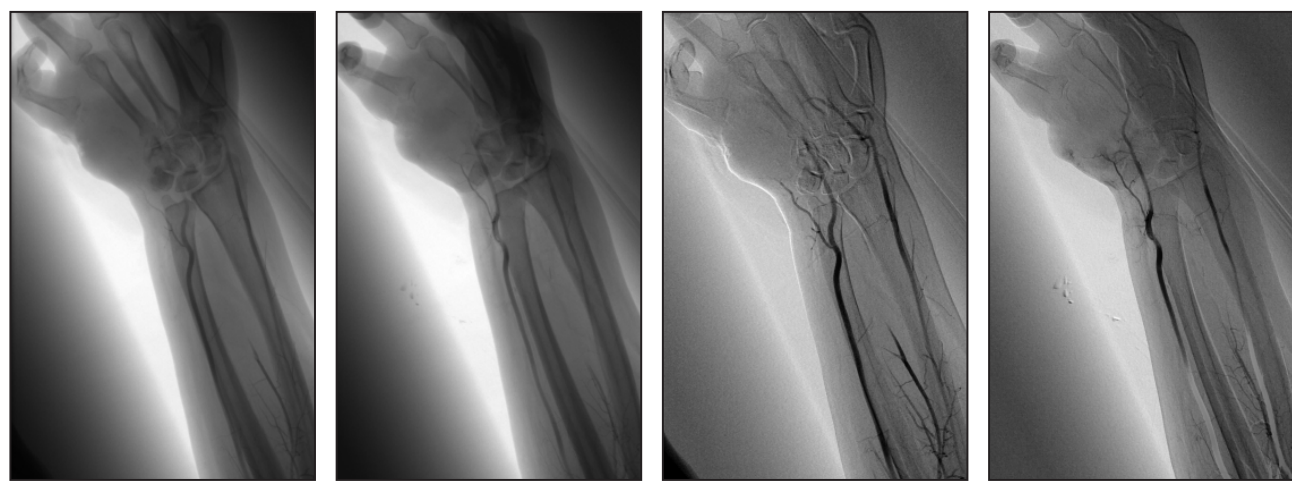

Figure 9. DSA images of 2009-11-03

third of the ulnar artery towards the macroscopically visible bulge. In the bulge region there is a tumor-specific malformed blood vessel network. The arch of the ulnar artery is slightly deviated towards radial, however the width and route of the digital arteries leading to the ring finger are normal. There is no abnormality in the radial arch. According to the DSA results, it was suggested, that in case of no other contraindications, the middle finger might as well be saved.

According to the DSA findings there seemed to be a good chance to retain opposition and grip. However the surgeon might have to face quite a number of surprises during tumor surgery.
During surgery attention was paid to the stabilization of the radial side and the preservation of the motor apparatus (Figure 10). To achieve it tendons of the brachioradial muscle, $\mathrm{mm}$. extensor carpi radialis longus et brevis, $\mathrm{mm}$. extensor pollicis longus et brevis, mm. extensor indicis longus et brevis and $\mathrm{m}$. extensor pollicis longus, on the palmar side tendons of $\mathrm{m}$. flexor carpi radialis, and flexor tendons, the small thenar muscles and $\mathrm{mm}$. lumbricales had to be preserved.

Special attention was paid to the motor branch of the median nerve, and its direct sequel the digital nerves of the thumb and index finger, that originate partly from this trunk, partly form a separate branch (Figure 11). 


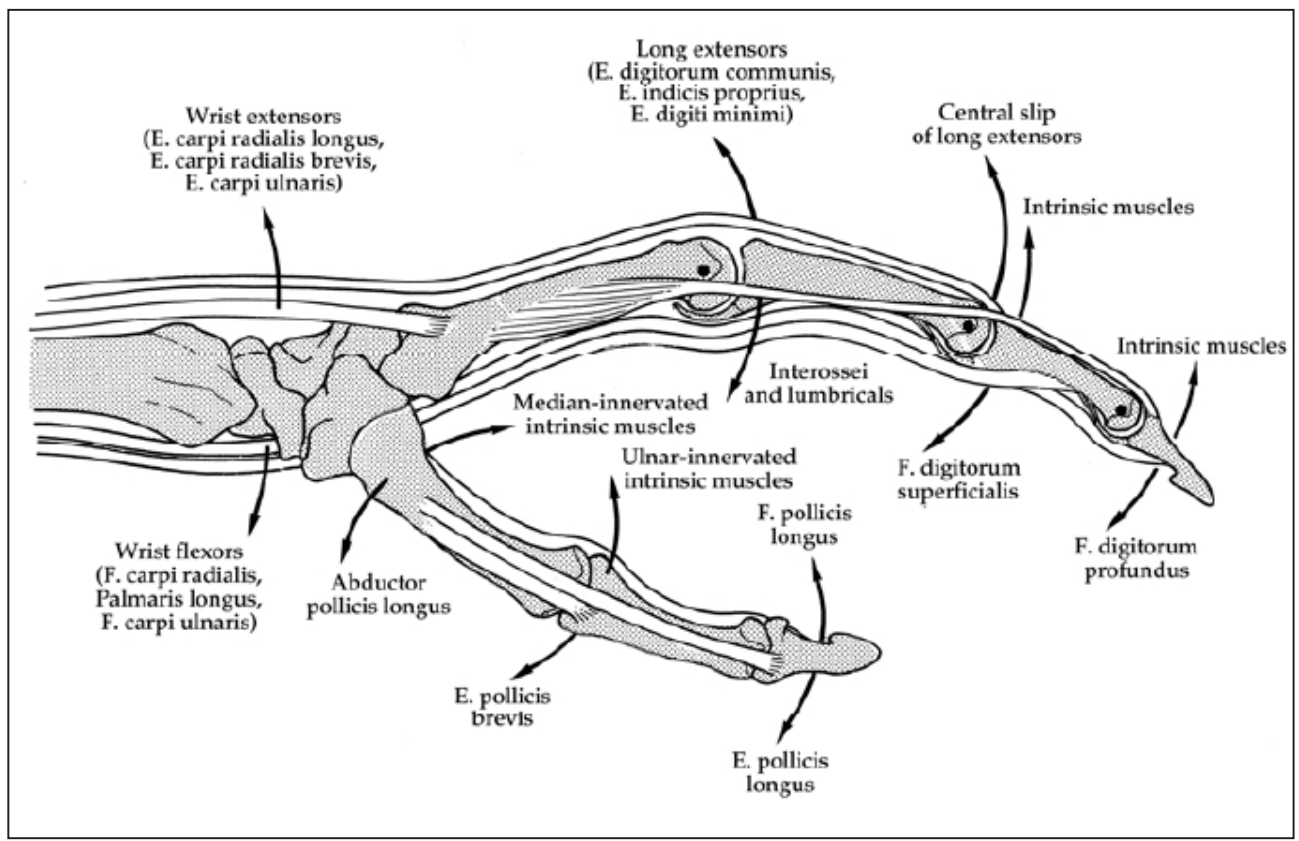

Figure 10. Radial side of the hand's movement apparatus ${ }^{1}$

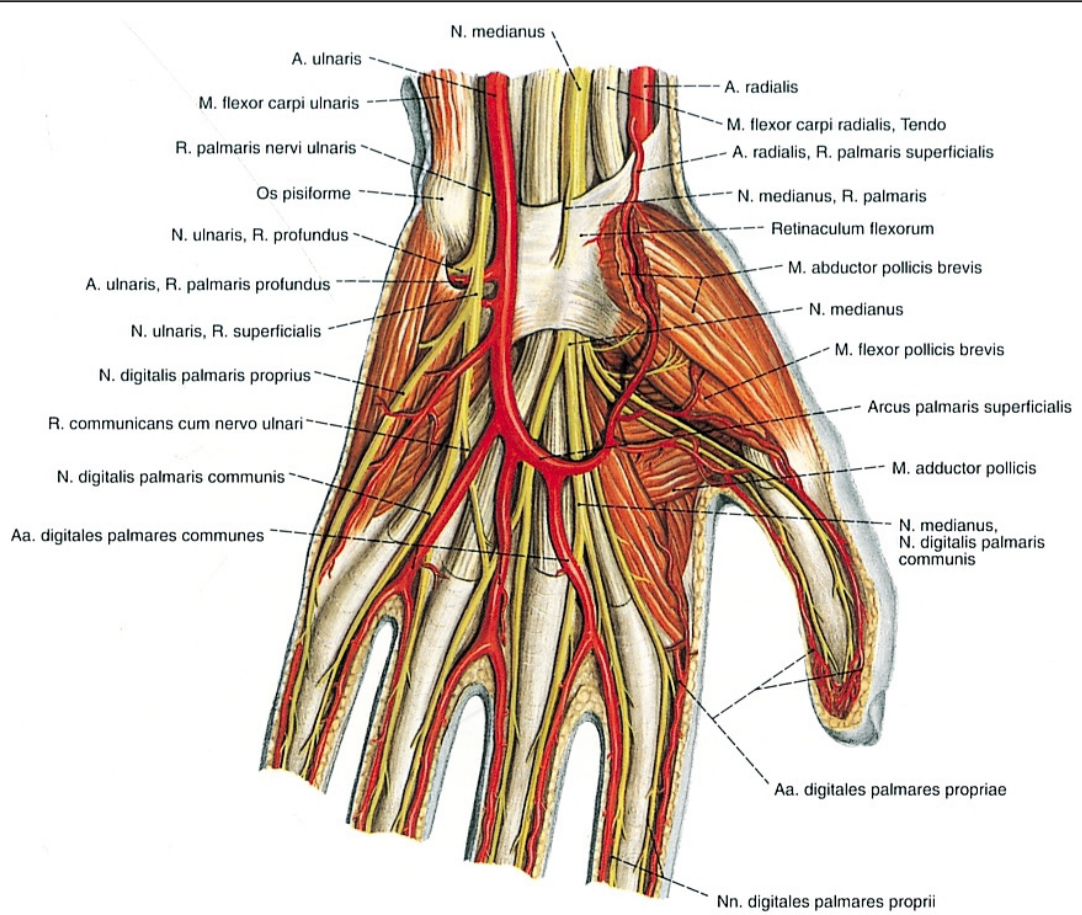

Figure 11. Nerves of the hand ${ }^{2}$ 


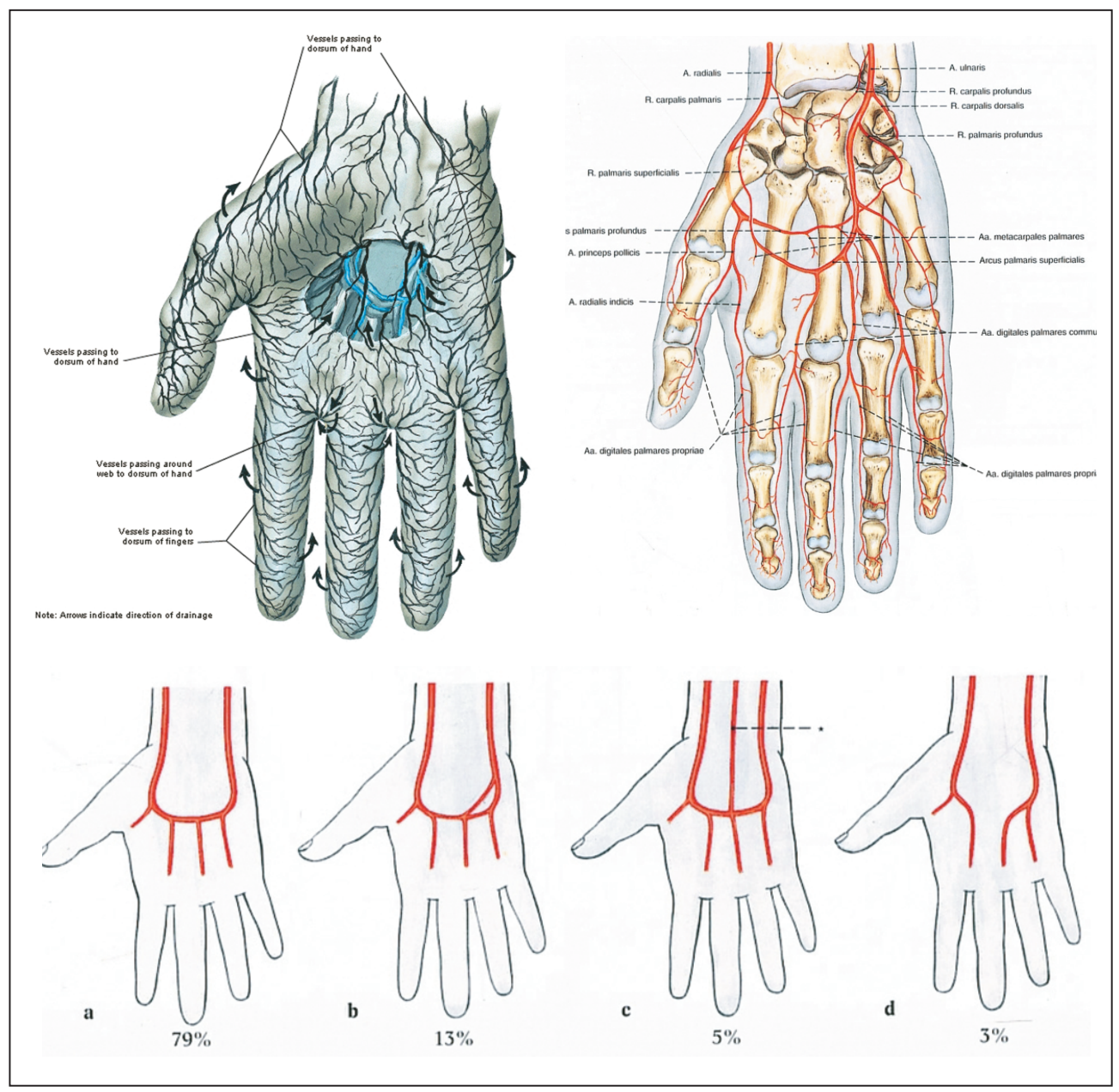

Figure 12. Anatomy of lymphatic vessels and arteries of the palm²

The superficial and deep palmar arterial branches had to be identified too, the latter having a large number of anatomical variations as shown in literature (Figure 12).

The surgery resulted in a resection that cleared the tumor by $6 \mathrm{~mm}$, but left a huge skin defect. The thumb and index finger became unstable due to the size of the resection, that is why an atypically placed $\mathrm{AO}$-plate was used to fasten them to the forearm (Figure 13). The surgery (Figure 14) was concluded by using the middle finger as a fillet flap (Figure 15).

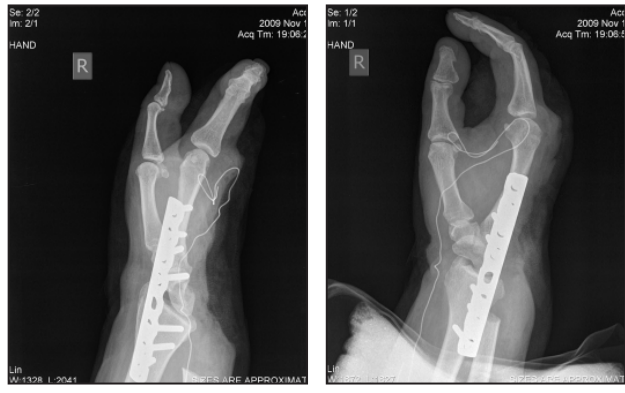

Figure 13.

Postoperative X-rays of 2009-11-16 showing fixation 
告

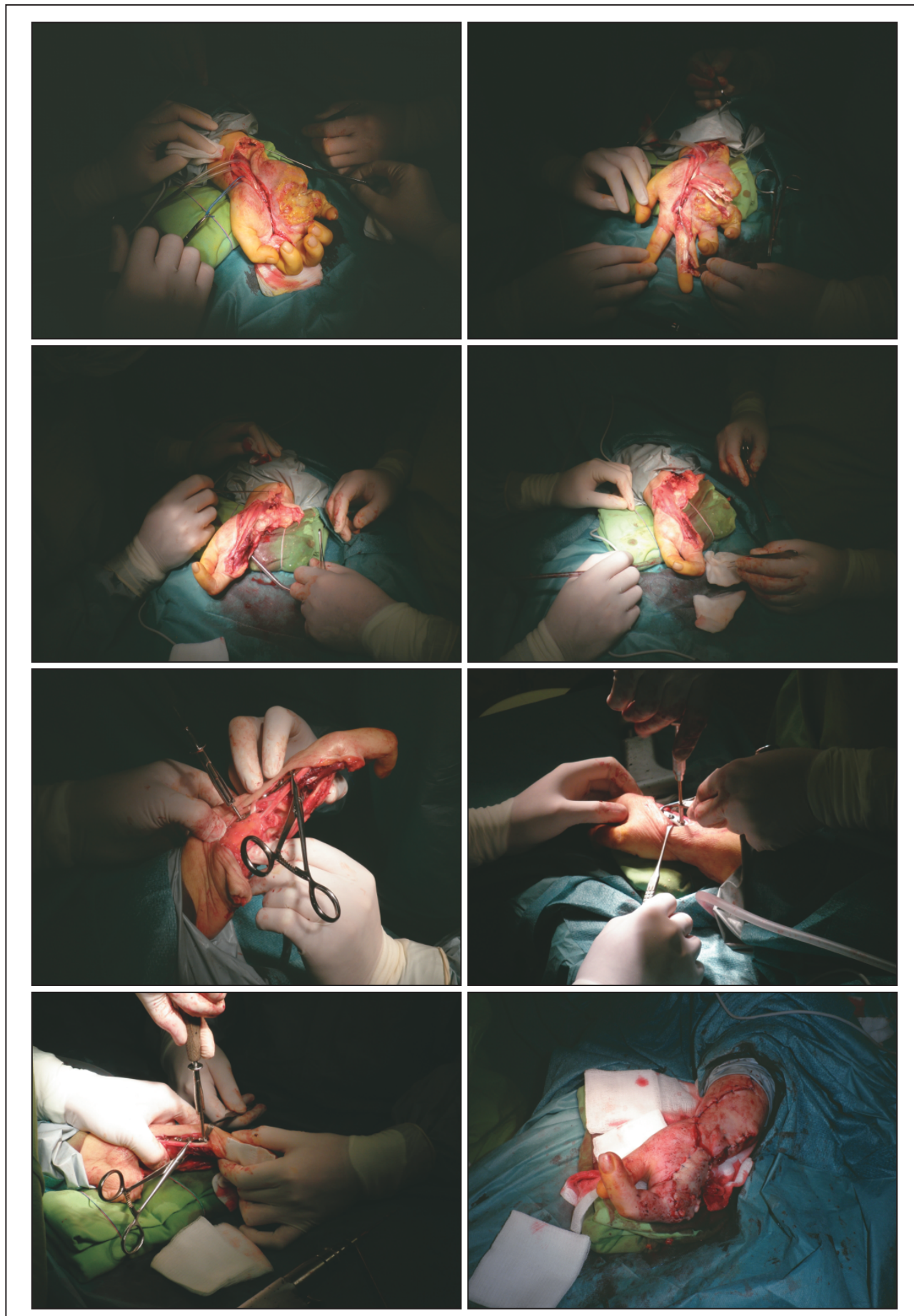

Figure 14. Snapshots from surgery of 2009-11-16 


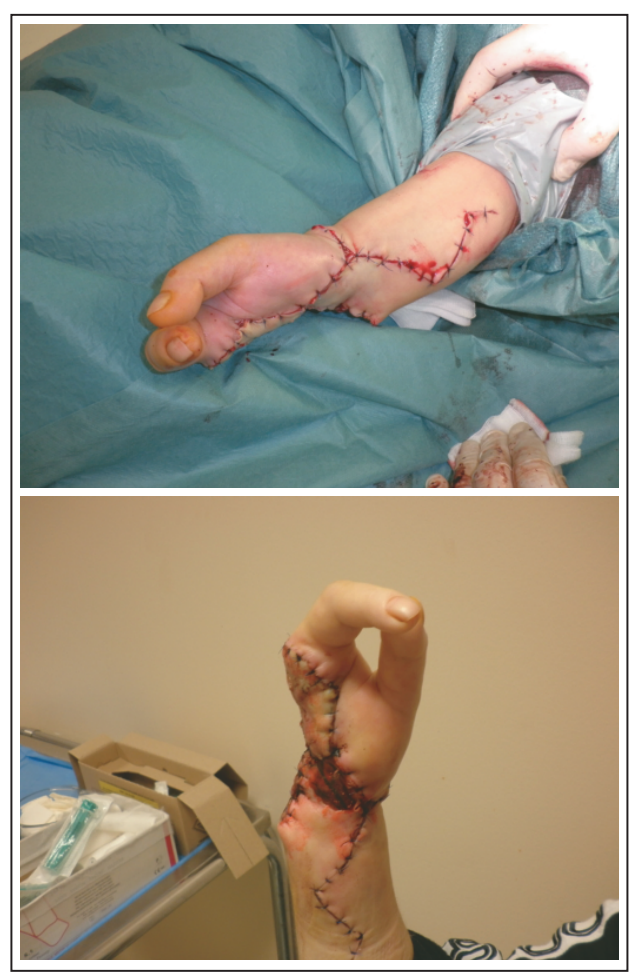

Figure 15. Result of surgery

Tissues of a patient after cytostatic therapy and hand irradiation can not be compared to those of a healthy person, their consistency caused a large number of technical difficulties.

The thorax CT of 2009-12-09 showed that infiltrated lymphnodes that can not be separated form the tumor in the lower left lung lobe dislocate, compress and infiltrate the oesophagus. There was a $2 \times 5 \mathrm{~cm}$ probable metastasis in the right suprarenal gland.

Mid-December percutan gastroenteral feeding had to be started because the tumor compressed the oesophagus $30 \mathrm{~cm}$ long.

50 days after surgery the patient was able to do opposition and grip with the remaining two fingers, and could handle small objects, like pens (Figure 16).
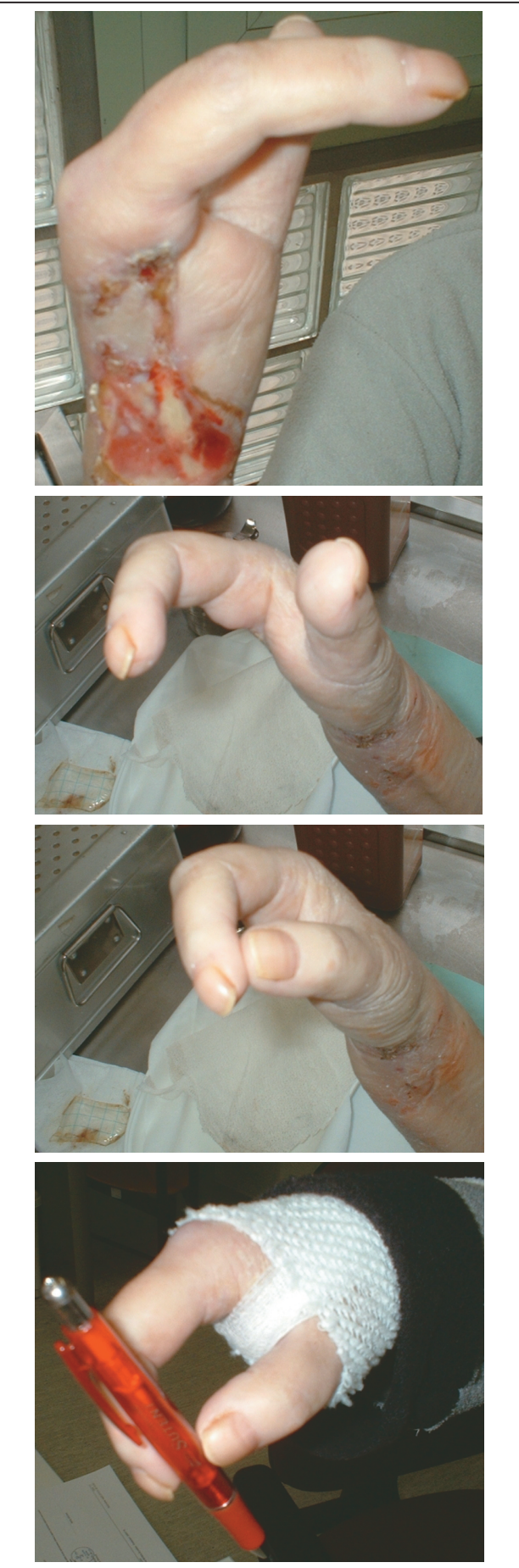

Figure 16. Functional results of 2010-01-04 
Unfortunately a few days later the patient died of general circulatory and respiratory insufficiency.

\section{Results \& conclusion}

It is often necessary to use ad hoc solutions in hand surgery, especially in cases of hand tumors. It is important to choose the ideal method from the repository of osthesynthesis techniques, because in such cases as shown in this paper, there is hardly a chance of a revision.

It is highly recommended to use statically terminal and biomechanically unorthodox solutions, like atypical plate placements.
In the presented case early consideration and the help of other specialists the adequate surgical planning promised the retainment of good function for the hand surgeon. However the patient's treatment nevertheless early recognition and appropriate diagnostic steps sidetracked from the point of hand surgical view, and later on only the severe tumor caused deformation could be treated with sever difficulties.

There seems to be no similar case yet, where the primary metastasis of the lung tumor appeared on the hand in both domestic and international literature.

\section{REFERENCES}

1. Beasley $R W$. Beasley's Surgery of the Hand. New York: Thieme, 2003.
2. Putz P, Pabst R. Sobotta. Az ember anatómiájának atlasza I-II. Budapest: Medicina, 2007.

\section{Miklós Szokoly}

Péterfy S. Hospital and Trauma Center

H-1081 Budapest, Fiumei út 17. 